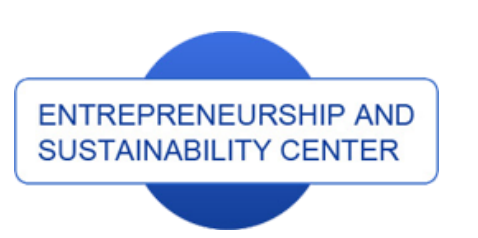

Publisher

http://jssidoi.org/esc/home

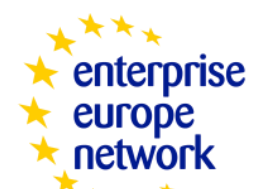

Business Support on Your Doorstep

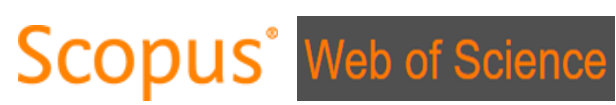

1) Clarivate

\title{
MEASUREMENT OF INFORMATION IN THE SUBSYSTEM OF INTERNAL CONTROL OF THE CONTROLLING SYSTEM OF ORGANIZATIONS OF THE AGRO-INDUSTRIAL COMPLEX *
}

\author{
Svetlana Bychkova ${ }^{1}$, Nadezhda Makarova ${ }^{2}$, Elena Zhidkova ${ }^{3}$ \\ ${ }^{1}$ Saint-Petersburg state agricultural University, St. Petersburg, Pushkin, Petersburg Highway 2, 196601, Russia \\ ${ }^{2}$ Volgograd Cooperative Institute (branch) of the Russian University of Cooperation, Volgograd, Novosibirskaya street, 76, \\ 400002, Russia \\ ${ }^{3}$ Kemerovo State University, Kemerovo, Krasnaya Street, 6, 650000, Russia
}

E-mails: ${ }^{1}$ smbychkova@mail.ru; ${ }^{2} y a m g @ m a i l . r u ;{ }^{3} 291154 @ m a i l . r u$

Received: 8 March 2018; accepted 8 May 2018; published 30 September 2018

\begin{abstract}
In accordance with the new management concept, based on some provisions of the system paradigm, the process subsystem of internal control of the controlling system of organizations of the agro-industrial complex is considered. The process system of internal control of agro-industrial complex organizations is primarily connected with the control of certain information systems that accumulate information on quantitative and qualitative indicators, taking into account the internal and external conditions of functioning of agroindustrial complex organizations, as well as management systems. The article describes the levels of information measurement in the process system of internal control: a syntactic level that does not express a semantic relation to the object; semantic level, which determines the semantic content of information; a pragmatic level that reflects the value, usefulness of using information. The research purpose was to formulate a conclusion that in the process system of internal control of the agro-industrial complex organizations, large amounts of information are needed to inform controlling information in order to obtain the opportunity to make effective decisions to eliminate deviations, thereby increasing the efficiency of business development of agro-industrial organizations.
\end{abstract}

Keywords: process system of internal control, controlling system, information, syntactic approach, semantic approach, pragmatic approach, business analytics, entropy.

Reference to this paper should be made as follows: Bychkova, S.; Makarova, N.; Zhidkova, E. 2018. Measurement of information in the subsystem of internal control of the controlling system of organizations of the agro-industrial complex, Entrepreneurship and Sustainability Issues 6(1): 35-43. http://doi.org/10.9770/jesi.2018.6.1(3)

JEL Classifications: D80, G 32, M 11, Q14, Q13

\footnotetext{
* The study was carried out with the financial support of the Russian Foundation for Basic Research within the framework of the scientific project 18-010-01096 «Neo-system approach as a factor of scientific justification of transformation of the fundamentals of controlling of agribusiness organizations».
} 


\section{Introduction}

The modern systemic minieconomics (economy of an economic entity), which is based on the provisions of the systemic paradigm, raises the question of the boundaries of systems that operate in an economic entity, and, as a consequence, the nature of the interactions of the internal institutional structure with the environment and, first of all, with information.

Today the structural organization of the agro-industrial complex (further - AIC) is represented by agricultural firms, agricultural factories, agricultural holdings and financial-industrial groups, which are based on the principles of horizontal and vertical integration. The most advanced management mechanism, such as the controlling system, including the subsystems of planning, accounting, control and analysis, is necessary for the effective operation of such organizations (Golovina, Golovin 2013; Golovina 2013). Many AIC organizations face an agency problem (agency problem) caused by information asymmetries and contract incompleteness. The agency problem in corporate governance becomes a source of risks of managerial opportunism of managers, which can lead to losses, damage the reputation of the AIC organization and reduce its value. With regard to organizational and managerial innovation, the ideas and experience of Western companies in the organization of the controlling system can be useful (Paseková et al. 2018, Ryabchenko et al. 2017; Svetlanská et al. 2018, Mokhova et al. 2018). The presence of an effective controlling system in an economic entity, one of the structural components of which is internal control, is considered a positive signal for partners and potential investors, which will best affect the growth of the company's capitalization and optimization of agency value.

The research purpose is to evaluate the measurement of information in the subsystem of internal control of the controlling system of organizations of the agro-industrial complex. In order to formulate a conclusion that in the process system of internal control of the agro-industrial complex organizations, large amounts of information are needed to inform controlling information in order to obtain the opportunity to make effective decisions to eliminate deviations, thereby increasing the efficiency of business development of agro-industrial organizations. Inductive and deductive, information's systematisation, comparison and summary methods were used for the research.

\section{Subsystem of control in the controlling system from the position of system economic theory}

The institutional subsystem "internal control", which has its own routines, is just one of the process subsystems of controlling, which is part of its complex design. The reference of internal control to the process subsystem of the controlling system is carried out depending on the belonging to the space-time characteristics: uncertainty in space; certainty in time. Each of the controlling subsystems can also be structured into separate units with certain types of systems. In this case, the internal control subsystem in the controlling system should be considered as an independent system (in our case, as an internal control system) with appropriate structuring of the main control components.

With regard to the context of this article, it is proposed to define internal control as a technological infrastructure that provides the organization and implementation of the process aimed at preventing errors and distortions of information for the effective conduct of activities and achievement of the goals. The process subsystem of internal control of the controlling system provides a balance in the spatial sense, completes the management cycle and acts as its result, using the results of accounting and analysis, assesses the adequacy of the implementation of the management decision, which resulted in a new management decision. In this regard, internal control becomes particularly important, since the quality of the generatedinformation does not always meet the needs of the business and management in AIC organizations. 
The process subsystem of internal control of the AIC organizations controlling system is connected, first of all, with the control of certain information systems, which store and accumulate information on quantitative and qualitative indicators, taking into account the internal and external conditions of functioning of the AIC organizations, as well as management systems. Consequently, the system of internal control is a qualitative side of controlling.

"Object" in the context of internal control is understood to mean the controlled link of the controlling system, which receives the control action. Depending on the system parameters (space constraints, time constraints), objects and their groups are combined in the course of systematic control in the object subsystem.

One of the most important attributes of the control system is the scale of control, which determines the ability of the system elements to receive and process information, solve more tasks and change strategies.

The solution of problems of complicationsin administrative tasks of strategic, tactical and operational levels on increasing volumes of information is assigned to the process subsystem of internal control of system of controlling. Under the information the authors understand "the object of perception, conversion, transmission and storage of a certain amount of information expressed by the signals, signs, messages, news, to eliminate uncertainty or to expand concepts about the world" (Shokhnekh, Makarova 2012, p. 146).

\section{Measurement of information in the process subsystem of internal control of the controlling system of agribusiness organizations}

The system of internal control in general in the beginning will be an information support of control activities of the organization AIC, which passes through the implementation of control functions (impact on each input at the appropriate time to achieve the desired output), and the output - information about the level of control of the object subsystem control.

The generated controlling information in the internal control system necessary for the management of the AIC organizations should be classified into two blocks: in relation to the controlled object (objects identified in the object subsystem of the internal control system; the type of communication of the object of control with the external environment; in relation to the target function of the object of control, logical content) and in relation to information technology, that is, to the processes of its collection, processing and provision (on the boundaries of fixation, the levels of additional processing before provision, universality, complexity, capacity, organization (ordering), the form of representation and the method of obtaining, the procedure of transformation, the degree of transformation).

Processing of information in the internal control system of AIC organizations should be considered from two positions: 1) the use of modern technologies and technical means in the work with the information under review; 2) identification and evaluation of objectively adequate volumes and flows of information.

Evaluation of information in the system of internal control can be carried out using the syntactic, semantic, pragmatic levels of information and using parameters such as the amount of information, the amount of data, the quality of information.

In view of the fact that the AIC organization, being the link of economic systems, operates in conditions of nonlinear development, internal control may face such a phenomenon as entropy of information.

From the position of the syntax level, the entropy method is used to measure the amount of information. 
The measure of chaos is associated withthe concept of entropy. In 1872, the Austrian physicist L. Boltzmann prudently identified entropy as a measure of chaos on the one hand with entropy as a measure of the missing information about the state of the system on the other. In the future, Shannon K. from different initial positions came to the same conclusion.

The first works on the theory of information is considered to be R. Hartley's articles (Hartley 1928), which first proposed a logarithmic measure of information (Hartley's amount of information) for equally probable events, as well as K. Shannon's publications (Shannon 1948), which determined the same for sets of events with different probabilities. On this basis, considering such properties of information as a novelty, would be surprise.

The most general definition of the amount of information in the probabilistic sense is described in the works of An. Kolmogorov (mid 50-ies of the last century). His work reflected an understanding of the universality of entropy as a measure of chaos regardless of nature. In addition, he developed another approach - the so-called algorithmic information theory, where entropy was understood as the complexity of the object, equal to the complexity of the algorithm describing the object (Kolmogorov 1987).

The relationship between entropy and information is reflected in the formula:

$\mathrm{H}+\mathrm{I}=1$,

where $\mathrm{h}$ is the entropy, I - information. This conclusion was quantified by the French physicist Leon Brillouin, who introduced the value of inverse entropy-negentropy, defined as entropy, taken with the opposite sign.

It should be noted that there is a relationship between information entropy and entropy thermodynamic, but it also denies their equivalence and identity. If earlier the concept of entropy was used only for systems seeking to thermodynamic equilibrium (to the maximum disorder in the motion of its components, to increase entropy), the concept of information drew attention to those systems that do not increase entropy, but on the contrary, being in a state with small values of entropy, strive for its further reduction (Bekman 2009).

It is the information in the object subsystem of the internal control system of AIC organizations that becomes a source of entropy, which is also an indicator of increasing deviations.

Large values of entropy are typical for a low-organized system (a system with a high disorder and chaos). Low entropy values are inherent in high structural ordering of a particular system. Thus, entropy serves as a measure of structural organization of the system. In the internal control system, self-organization occurs as a result of the emergence of local ordering of information. To make the right decision, you should have a certain amount of information to avoid overloading managers and specialists.

The semantic approach to information evaluation is used to determine the content side (subject value) of the received information. The logical-semantic theory of information was developed for the first time by W. BarHillel and R. Carnap. Based on the works of these authors K. E. Voishvillo (1966) subsequently combined information not directly from experience but from some judgments in which the entropy can be interpreted as the measure of accumulation of information. The measure of information depends on the surprise factor.

Russian scientist Yu. A. Schreider presented the semantic aspect of measuring the semantic content of information in a different way. He suggested using the thesaurus measure (Shreider 1971). Ideas about the thesaurus method were previously proposed by the founder of Cybernetics N. Wiener. In information theory, a thesaurus is a collection of information that a subject has. J. A. Schrader mapped out the representation of diversity, in which quantified semantic information is assessed through the level change of the thesaurus, i.e. through changes of the diversity of knowledge of the subject. 
Depending on the relationship between the semantic content of the information and the user's thesaurus, the amount of semantic information changes, while the nature of such dependence is reduced to the consideration of three main conditions under which the user's thesaurus (Yashin 2008):

* tends to zero (that is, the user does not perceive, does not understand the information received);

$*$ tends to infinity (i.e. the user thoroughly knows all about the object or phenomenon and received information it is not interested);

* agreed with the semantic content of the information (that is, the received information is clear to the user and carries new information).

The first two limit conditions characterize the state in which the user receives the minimum amount of information. The third means that the user obtained the maximum amount of semantic information. Therefore, "the amount of semantic information that is obtained is a relative value, because the same message can have meaning for a competent user and be meaningless for an incompetent user" (Yashin 2008, p. 11).

Semantic (semantic) alignment in the process subsystem of internal control of the controlling system is to prevent short-term and, most often, non-recurring distortions that could lead to a misalignment of forms of registration of accounting events with essential features of management.

At the pragmatic level, as an alternative to the semantic level, the amount of information is perceived from the point of view of achieving the goal set by the recipient (the usefulness of the message is evaluated). This aspect allows you otherwise, take into account such characteristics of information as value, usefulness, relevance, reliability, adequacy, and others, with a focus on identifying bottlenecks related to the process of communication in a different way.

The works of the academician A. A. Kharkevich within the framework of the mathematical theory of information should be highlighted. A. A. Kharkevich was one of the first researchers to study the problem of assessing information at a pragmatic level, proposing in his article a method for determining the measure of the value of information through the increment of the probability of achieving the goal when it is obtained (Kharkevich 1960). Thus, a pragmatic measure characterizes the value of information to the achievement of the objective of the office. M. M. Bongard approached the problem of the value of informationfrom a different position. He introduced the concept of "useful information", in which the message is associated the task that the recipient is solving what the recipient decides, and that he knows before the arrival of the message, as it interprets (Bongard 1967). This position has a probabilistic-algebraic essence, which makes it more general than A. Kharkevich's approach.

Of particular interest within the framework of pragmatic information theory is the behavioral model of communication by Akoff-Miles, which is based on the concept of "goal-oriented state", which allows to increase the probability of choosing the most effective option from the available alternatives to the best strategy to achieve the goal (Akoff, 1985). However, a weakness of the model is its lack of preparedness for the assessment of false reports.

The pragmatic properties of information are expressed only in the fact of the unity of information (object), user (subject) and the purpose of internal control. From the point of view of consideration of the pragmatic aspect, the emphasis is placed on the evaluation of the usefulness of information (content) in the development of consumer targeted solutions. This form of conformity directly relates to the practical use of information, the consistency of its target function of the system.

In the internal control system of AIC organizations the pragmatic level in the evaluation of economic information is the most important, because in determining the value of information guided by such criteria as usefulness. The 
usefulness of the information is that for making effective decisions under risk should use the information that is really necessary.

Table 1 presents the characteristics of the information levels in the process subsystem of internal control of the system controlling AIC organizations.

Table 1. Characteristics of measurement levels of information in the process subsystem of internal control of the system controlling organizations AIC

\begin{tabular}{|c|c|c|c|}
\hline \multirow[t]{2}{*}{ The name of the levels } & \multicolumn{3}{|c|}{ Characteristics of the level } \\
\hline & Measurement & $\begin{array}{l}\text { Amount of } \\
\text { information }\end{array}$ & Obtaining information \\
\hline $\begin{array}{c}\text { Syntax level (does not Express } \\
\text { a semantic relation to the } \\
\text { object) }\end{array}$ & $\begin{array}{l}\text { The amount of Vd data in a } \\
\text { message is measured by the } \\
\text { number of characters in that } \\
\text { message. Units of the } \\
\text { number system (often } \\
\text { binary) - bits or bytes and } \\
\text { their derivatives }\end{array}$ & $\begin{array}{l}\text { Is determined by the } \\
\text { uncertainty in the system } \\
\text { (entropy). The amount of } \\
\text { information is measured } \\
\text { by reducing the } \\
\text { uncertainty of the system } \\
\text { state }\end{array}$ & $\begin{array}{l}\text { The choice of one message } \\
\text { from a finite, predefined set of } \\
\mathrm{N} \text { is equal to the number of } \\
\text { equally probable messages. } \\
\mathrm{I}=\log _{2} \mathrm{~N}\end{array}$ \\
\hline $\begin{array}{l}\text { Semantic level (the semantic } \\
\text { content of information) }\end{array}$ & $\begin{array}{l}\text { The amount of Vd data in } \\
\text { the semantic sense (depends } \\
\text { on the information and the } \\
\text { amount of knowledge } \\
\text { necessary for its perception) }\end{array}$ & $\begin{array}{c}\text { The amount of } \\
\text { information } \mathrm{Ic}=\mathrm{f}(\mathrm{Sp}), \mathrm{Sp} \\
- \text { thesaurus user, Ic }- \\
\text { information perceived by } \\
\text { the user }\end{array}$ & $\begin{array}{c}\text { Accept the message } \\
\text { can be of high value to one } \\
\text { subject and be a meaningless } \\
\text { character set to another }\end{array}$ \\
\hline $\begin{array}{l}\text { Pragmatic level (value, } \\
\text { usefulness of using } \\
\text { information) }\end{array}$ & $\begin{array}{c}\text { Accept the message } \\
\text { can be of high value to one } \\
\text { subject and be a } \\
\text { meaningless character set to } \\
\text { another }\end{array}$ & $\begin{array}{c}\text { Amount of information } \\
\mathrm{IP}=\log \mathrm{R} 1 / \mathrm{r} 0 \\
\text { where } \mathrm{P} 0 \text { is the } \\
\text { probability of reaching } \\
\text { the goal before receiving } \\
\text { the message; } \\
\mathrm{P} 1 \text {-probability of } \\
\text { achieving the goal after } \\
\text { receiving the information }\end{array}$ & $\begin{array}{l}\text { The resulting information may } \\
\text { not change the probability of } \\
\text { achieving the goals: } \mathrm{P} 1=\mathrm{P} 0 \text {, } \\
\text { and then Ic }=0 \text {, and the } \\
\text { information is called empty. } \\
\text { The information obtained can } \\
\text { increase the probability of } \\
\text { achieving the goal, i.e. } \mathrm{P} 1>\mathrm{P} 0 \text {, } \\
\text { and, therefore, the quantitative } \\
\text { measure of the value of } \\
\text { information (pragmatic } \\
\text { information) Ic }=\text { log } \mathrm{P} 1 / \\
\text { P0 }>0, \text { i.e. it is positive. } \\
\text { In the case where the } \\
\text { probability of achieving the } \\
\text { goals decades and P1 < P0, } \\
\text { Ic = log P1 / P0 < } 0, \text { such } \\
\text { information will have a } \\
\text { negative sign and be perceived } \\
\text { as disinformation }\end{array}$ \\
\hline
\end{tabular}

On the syntactic level one should take into account the media type and method of displaying information, the transfer speed and processing, the symbols (code system) to represent information. However, the syntactic measure of information in the process subsystem of internal control system controlling agribusiness organizations is relative. The indicator of the syntactic measure of information is not so much its total volume as the property to reduce the uncertainty of knowledge about any system, object or phenomenon.

In general, the process of informatization in the process subsystem of internal control system controlling AIC organizations will be as follows:

$$
\mathrm{I} ß=H(\alpha)-H ß(\alpha),
$$


where $H(\alpha)$ is the initial information about the system (situations, risks, etc.), $\mathrm{H} \beta(\alpha)$ is the ultimate information,

I 3 - is the amount of information received (syntax measure of information).

If the internal control system recognizes the object subsystem of research (production, centers of economic responsibility, situation, risks, etc.), then the entropy is removed, then $\mathrm{H} \beta(\alpha)$ turns into 0 , and accordingly Iß becomes equal to $H(\alpha)$, that is, in this case, the information system starts with "0". This fact is taken into account when making a decision. The syntax approach uses the term "data", and the amount of data is related to the number of instances of documents, the number of records in the database, and so on.

The semantic measure indicates the property of the user to assimilate the received information. In the present case, such a user is the controller. This circumstance directly involves a set of information (knowledge) about any object or event available to the controller (user) or the system as a whole.

To obtain an objective assessment of the amount of information at the semantic level, thecontent coefficient is used.

The volume of information received by the controller represents a relative value. It is more due to their level of fitness (competence) to perform the reception of messages or data. To carry out an objective assessment of the amount of information at the semantic level, the content coefficient $\mathrm{C}$ is used, which is determined by the following formula:

Where

$$
\mathrm{C}=\mathrm{Ic} / \mathrm{Vd}
$$

Ic- is the amount of semantic information,

Vd- is the total amount of information.

A pragmatic measure of information determines its usefulness, and the value for the system of internal control. This measure is primarily determined by the value of the price of information in each case.

It should be noted that in assessing the amount of information from the point of view of semantic and pragmatic levels, it is necessary to take into account the temporary dependence of information, since in the internal control system it has the feature of aging (losing value). Therefore, it is especially important to use the information at the moment of greatest value. In the system of internal control, first of all, it is necessary to achieve an increase in the accuracy of the analyzed, evaluated and predicted information in aggregate. In the controlling system, with the correct use of information, the AIC organization can provide its competitive advantages and in the future increase its value.

The modern AIC organization pursuing the purpose-increase of efficiency of activity, is inconceivable without the optimum system of controlling based on use of new information technologies and the latest computing equipment. Processing of data related to internal control is one of the main actions taken over the information, and it is carried out with the help of business intelligence tools. In today's world, the conventional reduction "BI" is generally accepted, which means only the part of business intelligence that provides the development and use of business information analysis technologies.

Business Analytics is a real subject technology of extracting semantic and pragmatic meaning of information.

At the time of receipt of information from various sources of information a syntax and semantic data harmonizationis carried out, automatically identifying syntax errors and incompatibility formats, as well as their correction and formatting. Syntax differences (different encoding of the same file attributes, different variants of 
The International Journal

ENTREPRENEURSHIP AND SUSTAINABILITY ISSUES

ISSN 2345-0282 (online) http://jssidoi.org/jesi/ 2018 Volume 6 Number 1 (September) http://doi.org/10.9770/jesi.2018.6.1(3)

names for this set of attributes with identical values, or the same names for attributes with different values) are subject to unification or differentiation according to certain rules of the subject area of ranking.

Semantic errors (such as missing data values in an unknown format or semantic errors in live source data) are identified and documented using domain validation criteria. Further, semantic harmonization of the data collected in accordance with production and economic, subject and time requirements is carried out.

In a pragmatic sense, at the entrance of the internal control system, only those that are necessary and sufficient to display a reliable picture of the state of agricultural business at a certain point of time are selected from the totality of the observed indicators.

The reliability of the information is supported by the relevant organization of the information system aimed at reducing the transaction information flows.

The use of information systems of class BI (Business Intelligence) or innovative cognitive service Watson Analytics as a tool of internal control APK provides a solution to key tasks: the organization of information and analytical support for the objective study of the activities of the cyclical nature of agricultural production; identify negative factors with the aim of maintaining economic security and improving the efficiency of management in agribusiness companies.

\section{Conclusions}

Under research results it may be concluded, that meta-controlling, which includes a process system of internal control as an integral part, acting in the framework of a unified information space of the organization of agriculture. The process subsystem of internal control of the controlling system penetrates the information space in almost real time and acts on the controlling system, adjusting it to the changing conditions of activity in the rapid receipt of information.

\section{References}

Akoff, R. 1985. Planning for the future of the corporation. Moscow: Published by Progress.

Bekman, I. N. 2009. Informatics: a course of lectures. Moscow-Rome: Published by MSU. Retrieved from http://profbeckman.narod.ru/InformLekc.htm

Bongard, M. M. 1967. The Problem of Recognition. Moscow: Published by Nauka.

Golovina, T. A. 2013. Concept Application «Management Future» for Forecasting of Financial Results Industrial Enterprises, Contemporary Economic Issues 1. http://doi.org/10.24194/11304

Golovina, T. A., Golovin, R. A. 2013. Organization of System of Administrative Strategic Control of Expenses for Production and Realization of Production of the Industrial Enterprise, Contemporary Economic Issues 2. http://doi.org/10.24194/21304

Hartley, R.V. L. 1928. Transmission of Information, Bell System Technical Journal 7(3): 535-563.

Kharkevich, A. A. 1960. On the Value of Information, Problems of Cybernetics 4: 53-57.

Kolmogorov, A. N. 1987. Theory of Information and Theory of Algorithms. Moscow: Published by Nauka. 
The International Journal

ENTREPRENEURSHIP AND SUSTAINABILITY ISSUES

ISSN 2345-0282 (online) http://jssidoi.org/jesi/ 2018 Volume 6 Number 1 (September) http://doi.org/10.9770/jesi.2018.6.1(3)

Mokhova, N.; Zinecker, M.; Meluzín, T. 2018. Internal factors influencing the cost of equity capital, Entrepreneurship and Sustainability Issues 5(4): 827-845. http://doi.org/10.9770/jesi.2018.5.4(9)

Paseková, M.; Müllerová, L.; Crhová, Z.; Svitaková, B. 2018. Impact of reporting of deferred tax on sustainable development of a counry: case of Czech Republic, Journal of Security and Sustainability Issues 7(4): 769-779. https://doi.org/10.9770/jssi.2018.7.4(13)

Ryabchenko, O.; Golub, G.; Turčeková, N.; Adamičková, I.; Zapototskyi, S. 2017. Sustainable business modeling of circular agriculture production: case study of circular bioeconomy, Journal of Security and Sustainability Issues 7(2): 301309. https://doi.org/10.9770/jssi.2017.7.2(10)

Shannon, C. E. 1948. A Mathematical Theory of Communication, Bell System Technical Journal 27: 379-423.

Shokhnekh, A. V., Makarova, N. N. 2012. Theory and methodology of the formation of control analytical procedures for assessing the development and application of information technologies, Bulletin of International Academy of Agrarian Education 2(15): 145-156.

Shreider, Yu. A. 1971. Thesaurus in Informatics and Theoretical Semantics, Information languages. STI. Ser. 2 3: 21-24.

Svetlanská, T.; Turčeková, N.; Adamičková, I.; Skalský, R. 2017. Food security facets: case of Slovakia regions, Journal of Security and Sustainability Issues 7(2): 311-320. https://doi.org/10.9770/jssi.2017.7.2(11)

Voishvillo, K. E. 1966. An attempt at a semantic interpretation of statistical concepts of information and entropy. Moscow: Published by Mysl.

Yashin, V. N. 2008. Informatics: personal computer hardware. Moscow: Published by Infra-M.

Svetlana Mikhailovna BYCHKOVA is Doctor of Economic Sciences, Professor, Head of the Department of Accounting and Audit, St. Petersburg State Agrarian University, St. Petersburg, Russia. Research interests: audit methodology, controlling.

ORCID ID: orcid.org/0000-0001-7684-9025

Nadezhda Nikolaevna MAKAROVA is Doctor of Economic Sciences, Associate Professor, Professor of the Department of Economic Security and Information Technologies, Volgograd Cooperative Institute (Branch) of the Russian University of Cooperation, Volgograd, Russia. Research interests: system analysis, controlling, economic safety.

ORCID ID: orcid.org/0000-0001-9305-0477

Elena Anatolyevna ZHIDKOVA is Candidate of Economic Sciences, Associate Professor, Head of the Department Accounting, Analysis, Audit and Taxation, Kemerovo, Russia. Research interests: controlling, entrepreneurial structures of agro-industrial complex.

ORCID ID: orcid.org/0000-0002-7658-0254

Register for an ORCID ID:

https://orcid.org/register

Copyright (C 2018 by author(s) and VsI Entrepreneurship and Sustainability Center

This work is licensed under the Creative Commons Attribution International License (CC BY).

http://creativecommons.org/licenses/by/4.0/

(C) (i) Open Access 